\title{
Cambios en el papel económico de las mujeres entre las parejas mexicanas
}

\section{Marcela Cerrutti* \\ René Zenteno**}

El presente trabajo se centra en el estudio de los cambios recientes más importantes en el papel económico de las mujeres entre las parejas mexicanas de las principales áreas urbanas de México. El énfasis en la pareja, tradicionalmente identificada como el jefe de hogar y su cónyuge en las encuestas de hogares, se fundamenta no sólo por el hecho de que han sido las cónyuges quienes han experimentado los aumentos más significativos en su participación económica durante la última década, sino también por la centralidad que tienen las parejas en el estudio de las relaciones de género. Nuestro trabajo empírico parte de la premisa de que la dependencia económica de las cónyuges es uno de los mecanismos centrales mediante los cuales se subordina a las mujeres en la sociedad, y de que la generación de un ingreso independiente por concepto de trabajo constituye una base material crítica para la toma de decisiones por parte de las mujeres. La información de la Encuesta Nacional de Empleo Urbano para el periodo 1987-1997, muestra que aunque la dependencia económica de las mujeres entre las parejas mexicanas ha disminuido, sus niveles continúan siendo altos en relación con las pautas observadas en los países más desarrollados. Además, durante la pasada década la mayor participación económica de las cónyuges no se reflejó en un incremento de sus contribuciones monetarias. En general, puede argumentarse que el comportamiento económico de las cónyuges parece ser más el producto de circunstancias económicas apremiantes que resultado de transformaciones profundas en la condición social de la mujer en la sociedad mexicana. El presente trabajo muestra empíricamente la importancia de analizar los arreglos laborales existentes entre las parejas mexicanas. Esto permite apreciar el carácter complementario de la actividad económica de las parejas y su naturaleza empresarial, pues después de la combinación ambos miembros trabajando como asalariados con beneficios laborales, es la combinación jefe patrón o trabajador por cuenta propia y cónyuge trabajadora no remunerada la que concentra un mayor número de parejas económicamente activas. La evidencia muestra también que las condiciones laborales de jefes y cónyuges sufrieron un deterioro importante durante la última década, y que esta situación afectó a parejas en distintas etapas del ciclo de vida familiar. La relevancia de centrar el análisis en los arreglos laborales de las parejas se confirma con los resultados de regresión multivariada, los cuales muestran claramente que la participación económica de las cónyuges, así como su contribución a los ingresos de las parejas, no está únicamente vinculada a las características individuales y familiares de las mujeres, sino también a las condiciones laborales de los jefes de hogar.

* Universidad de Pennsylvania y Centro de Estudios de Población de Argentina. Correo electrónico: cerrutti@pop.upenn.edu

** Centro de Estudios Estratégicos y Centro de Investigación Demográfica e Información Geográfica, ITESM-campus Guadalajara. Correo electrónico: rzenteno@campus. gda.itesm.mx 


\section{Introducción}

La creciente incorporación de las mujeres al mercado de trabajo constituye una de las transformaciones sociales recientes de mayor relevancia en las sociedades latinoamericanas. En el caso de México, el aumento de la participación de la mujer en actividades económicas extradomésticas, y los cambios en el perfil sociodemográfico de la fuerza de trabajo femenina, son acontecimientos ampliamente documentados en la literatura sobre el tema. ${ }^{1}$ Cambios en la estructura social y familiar, así como la persistente reestructuración y crisis económica, han contribuido a un incremento significativo de la oferta de trabajo femenino. Más aún, cambios recientes en los patrones de reproducción de la familia, tales como aumentos en las tasas de separación y divorcio, en la migración masculina y en las jefaturas de hogar femeninas, se encuentran asociados a una mayor incorporación de las mujeres al mercado de trabajo. Estas transformaciones han sido a la vez resultado y motor de cambios significativos en las relaciones de género.

Diversos estudios sobre hogares y trabajo femenino han revelado la existencia de conflictos importantes entre los valores normativos y el cambio socioeconómico asociado con la creciente participación de las mujeres en el mercado de trabajo. Si bien mujeres con altos niveles educativos continúan incorporándose al mercado de trabajo con cierta independencia de las condiciones de la economía, la mayoría de las mujeres mexicanas no muestran todavía una marcada inclinación por el trabajo fuera del hogar, en particular cuando existe una fuerte tensión para combinar trabajo doméstico y extradoméstico (García y Oliveira, 1994).

Aun en una sociedad tradicional como la mexicana, el incremento y la diversidad de la experiencia laboral de las mujeres han implicado una erosión de las prescripciones normativas acerca de su papel, en particular en relación con la ideología de la reproducción. Mujeres que trabajan y que generan su propio ingreso son las que más probablemente tengan un mayor control reproductivo (Roldán, 1988), y una participación más activa en la toma de decisiones, incluyendo matrimonio, sexualidad y divorcio (Blumberg, 1991; Cerrutti, 1997).

\footnotetext{
${ }^{1}$ Para estudios sobre la evolución del trabajo femenino en México y sobre sus determinantes véase García y Oliveira, 1994; Christenson, García y Oliveira, 1989; González de la Rocha, 1990; Cerrutti, 1997; Fussell y Zenteno, 1998, y Zenteno, 1998.
} 
Estos cambios en los valores tradicionales se han producido lentamente y no sin conflictos y ambigüedades (Tiano, 1994).

Aunque existe cierto consenso sobre las repercusiones positivas del trabajo extradoméstico para las mujeres en términos de su mayor independencia, confianza en sí mismas y autonomía en la toma de decisiones familiares, dichas repercusiones se encuentran mediatizadas por la experiencia real del trabajo que desarrollan.

Las modificaciones que la experiencia laboral de las mujeres puede introducir al significado de la división sexual del trabajo tradicional están vinculadas a tres factores estrechamente relacionados entre sí. Primero, al tiempo dedicado a las actividades domésticas vis a vis las económicas. Segundo, al tipo y las condiciones del trabajo de la mujer. Las variadas formas de inserción de la mujer en el mercado de trabajo ya sea participando de manera regular o intermitente, ${ }^{2}$ laborando çon o sin remuneración, por tiempo completo o parcial, como asalariada $a^{3}$ o como trabajadora independiente, en tareas que demandan diferentes niveles de calificación y en condiciones laborales muy diversas (en términos de retribución a la experiencia, obtención de beneficios laborales, etc.) influyen de manera distinta las relaciones de género (Benería y Roldán, 1987; Cerrutti, 1997). Tercero, al nivel de los ingresos generados por las mujeres trabajadoras en relación con el conjunto de ingresos del hogar.

El presente estudio examina la evolución reciente del trabajo femenino y de su papel económico en el contexto de las parejas que encabezan los hogares en las principales áreas urbanas de México. El énfasis en la pareja, tradicionalmente identificada como el jefe de hogar y su cónyuge en las encuestas de hogares, se fundamenta no sólo por el hecho de que han sido las cónyuges quienes han experimentado los aumentos más significativos en su participación económica durante la última década, sino también por la centralidad que tienen las parejas en el estudio de las relaciones de género. Específicamente, en este trabajo nos proponemos, en una primera instancia, describir la relación entre el trabajo extradoméstico de las cónyuges y la erosión

${ }^{2}$ Los cambios de actitud en relación con los roles de género debido a la menor dependencia económica son más probables de producirse si la mujer trabaja por periodos más prolongados (Huber y Spitze, 1983).

${ }^{3}$ Como apunta Safa (1995), el aumento del trabajo asalariado femenino, en particular de las mujeres casadas, necesariamente conlleva a una redefinición en la división sexual del trabajo dentro de los hogares. 
del modelo tradicional del "jefe de hogar" como único proveedor económico, así como identificar las principales características tanto de la mujer como del hombre asociadas con la participación de las cónyuges en actividades económicas.

Tradicionalmente los estudios sobre los determinantes de la participación femenina en los mercados de trabajo se han centrado fundamentalmente en la influencia de dos conjuntos de características: su capital humano (educación formal, no formal e informal, experiencia laboral previa, etc.) y el ciclo de vida individual y familiar (edad, estado civil, posición en el hogar, número y edad de los hijos, estructura familiar, etc.). Sin embargo, en este trabajo proponemos indagar la relación entre el trabajo de la cónyuge y el del jefe. Nuestro punto de partida es que es muy probable que ni la propensión a trabajar, ni el trabajo que efectúa la mujer, ni su nivel relativo de ingresos sean independientes de la naturaleza y características del trabajo de su pareja. Proponemos por lo tanto comenzar a indagar sobre los posibles arreglos laborales entre miembros de la pareja, es decir las particulares circunstancias (en términos de tipo de trabajo, condiciones laborales, horas trabajadas, etc.) que facilitan (o restringen) la participación de ambos miembros de la pareja en actividades económicas. En el contexto actual de creciente participación de las mujeres en actividades económicas extradomésticas, de escaso (o inexistente) apoyo institucional para parejas trabajadoras, y de creciente inestabilidad en el empleo, el concepto de arreglos laborales aparece como promisorio no sólo para la mejor comprensión de los determinantes del empleo femenino, sino también de los ingresos diferenciales entre hombres y mujeres. Cabe señalar que los arreglos laborales entre parejas no son necesariamente resultado de una adecuación de las decisiones de las mujeres a las de sus cónyuges, sino que pueden ser producto también de decisiones coordinadas con un gran sentido de interdependencia entre las parejas, o de decisiones independientes de las mujeres.

En segundo lugar, y como una extensión de lo anterior, en el presente trabajo sé examinan los cambios en la contribución económica de la mujer en relación con los ingresos generados por la pareja, y se identifican los principales determinantes de dicha contribución.

Al respecto, nuestro punto de partida es que la dependencia económica de las cónyuges es uno de los mecanismos centrales mediante los cuales se subordina a las mujeres en la sociedad (Hartman, 1976; Barrett, 1980). La generación de ingresos independiente por concepto de trabajo, constituye una base material crítica para la toma de decisiones por parte de las mujeres. Como lo señalara Blumberg (1991), 
la importancia relativa hombre/mujer en la generación y el control de los ingresos y otros recursos en los hogares constituye uno de los principales determinantes de una serie de variables dependientes que van desde el control del propio cuerpo hasta el grado de poder dentro del matrimonio (Hood, 1983; Mason, 1996).

A pesar de la centralidad de la temática, pocos estudios se han referido a los cambios, características y condicionantes de la contribución de la mujer en el total de los ingresos del hogar en México. García y Oliveira (1994), basadas en entrevistas en profundidad, analizaron el tipo de gasto que efectúan las mujeres con su propio ingreso, en función de su nivel socioeconómico y el compromiso con su trabajo. Son las mujeres de clase media, con un alto compromiso con sus carreras laborales las que realizan las contribuciones económicas centrales para el mantenimiento de sus hogares. Entre las mujeres de sectores populares, "está más claramente delineada la idea de que el varón es el principal responsable por la manutención básica y que él debe aportar para el gasto" (p. 204). Así y todo, prácticamente la mitad de estas mujeres declararon que su contribución económica al hogar es indispensable. Sin embargo, estas autoras reconocen la ausencia de un diagnóstico actualizado y representativo sobre la contribución de las mujeres al presupuesto de los hogares para el caso de México. Nuestra investigación pretende contribuir modestamente al conocimiento de esta dimensión del trabajo de la mujer.

La base empírica de la investigación es proporcionada por la Encuesta Nacional de Empleo Urbano (ENEU), la cual recopila información de calidad sobre las características laborales de la población económicamente activa en cerca de 50 centros urbanos del país. ${ }^{4}$ Para nuestro análisis utilizamos la información correspondiente a las 16 principales áreas metropolitanas originalmente incluidas en la encuesta, pues únicamente para éstas se cuenta con información comparativa para el periodo $1987-1997 . .^{5}$

${ }^{4}$ Desafortunadamente, esta fuente de información no permite examinar los patrones de distribución, control monetario y destino de los ingresos generados por las mujeres. Como lo mostraron Benería y Roldán en su estudio sobre trabajo a domicilio y dinámica de la unidad doméstica de México, estos factores constituyen el punto esencial de un estilo de interacción conyugal: "Los circuitos de asignación y los puntos de control, sus tensiones y conflictos, pueden considerarse no sólo como desenlace sino también como condición de renegociación de poder entre marido y esposa" (1987: 141).

${ }^{5}$ Las bases de datos incluyen las siguientes áreas metropolitanas: Ciudad de México, Guadalajara, Monterrey, Puebla, León, Torreón, San Luis Potosí, Mérida, Chihuahua, Tampico, Orizaba, Veracruz, Ciudad Juárez, Tijuana, Matamoros y Nuevo Laredo. 
El trabajo se divide en cuatro secciones. En la primera de ellas se documentan los cambios más importantes en la participación económica de las mujeres en el contexto de sus parejas. En la segunda se examina, mediante la estimación de un modelo de regresión logística, la influencia de las características laborales del jefe de hogar en la propensión de las cónyuges a participar en actividades económicas extradomésticas. $\mathbf{E l}$ análisis temporal de la inserción laboral de jefes y cónyuges se presenta en una tercera sección del documento. Finalmente, se estudia la evolución de la percepción relativa de ingresos por parte de cónyuges y jefes, y se presentan resultados de un modelo de regresión lineal (mínimos cuadrados) con el fin de determinar la influencia de características individuales, del hogar, del jefe y de la relación entre ambos miembros de la pareja sobre la contribución económica de las cónyuges.

\section{Trabajo extradoméstico de las cónyuges: 1987-1997}

Durante el periodo 1988-1997, la tasa de participación femenina en el conjunto de áreas metropolitanas aumentó en $24 \%$, al pasar ésta de 32.8 a $40.6 \%$. Si bien hoy en día las mujeres presentan una mayor probabilidad de formar parte de la fuerza de trabajo, existen aún contrastes importantes en la intensidad con que distintos grupos de mujeres laboran en actividades extradomésticas. Asimismo, existen marcadas diferencias en la magnitud del crecimiento de las tasas de participación económica por parte de mujeres con diversas características.

El cuadro 1 presenta la evolución de las tasas de participación económica femenina según la estructura de parentesco en los hogares entre 1987 y 1997. La información muestra claramente que las jefas de hogar son quienes muestran los niveles más altos de participación económica, mientras que las cónyuges los más bajos. No obstante la menor propensión de las cónyuges de incorporarse a la fuerza de trabajo, fueron éstas quienes experimentaron el mayor incremento relativo de sus tasas de participación durante el periodo $(32 \%)$. La magnitud del cambio en la participación de las cónyuges es más que evidente al observar que, en 1997, éstas laboran con la misma intensidad que lo hacían una década atrás todas las mujeres de 12 años y más. 


\section{CUADRO 1}

Tasas de participación de las mujeres en actividades económicas extradomésticas según la relación de parentesco con el jefe del hogar. Áreas urbanas de México, 1987-1997*

\begin{tabular}{lccc}
\hline Relación de parentesco & & & $\begin{array}{c}\text { \% Cambio } \\
1987-1997\end{array}$ \\
\hline Jefas & 1987 & 1997 & 57.5 \\
Cónyuges & 51.1 & 33.5 & 12.5 \\
Hijas & 25.3 & 44.3 & 32.4 \\
Otras miembros del hogar & 34.5 & 39.5 & 28.4 \\
Total & 32.2 & & 22.7 \\
\hline
\end{tabular}

* Tasas de participación por cien.

Fuente: Encuesta Nacional de Empleo Urbano, abril-junio de 1987 y 1997, INEGI. Datos procesados por los autores.

¿Qué tanto se explica este cambio en la participación de las cónyuges por cambios intergeneracionales en donde, las mujeres casadas jóvenes tienen una más alta probabilidad de trabajar que aquellas más adultas? La respuesta a esta pregunta es: muy poco. La gráfica 1 ilustra claramente dos puntos. Por un lado, que son las cónyuges en edades intermedias, 30 a 49 años, quienes tienen las tasas de participación más altas. Por el otro, que el cambio en la participación económica de las cónyuges ocurrió en todas las edades, pero especialmente entre las de 40 a 49 años. La gráfica también permite apreciar que el cambio entre las cónyuges durante el periodo 19871997 siguió un patrón muy similar al observado en el resto de las mujeres.

Aunque lejos de llegar a los niveles observados en los países desarrollados, la mayor participación de las cónyuges ha tenido una gran repercusión en el resquebrajamiento del modelo tradicional del jefe masculino como único proveedor económico del hogar. El cuadro 2 muestra la distribución de los hogares con al menos un miembro económicamente activo, según tipo de hogar y condición laboral de la pareja cabeza del hogar. La información permite argumentar, en primer lugar, que el aumento en la participación de las cónyuges está débilmente asociado con una transformación de la estructura de los hogares mexicanos durante el periodo 1987-1997, pues dicha estructura mostró cambios mínimos. Tres cuartas partes 


\section{GRÁFICA 1}

Tasas de participación económica de las cónyuges por edad. Áreas urbanas de México, 1987 y 1993

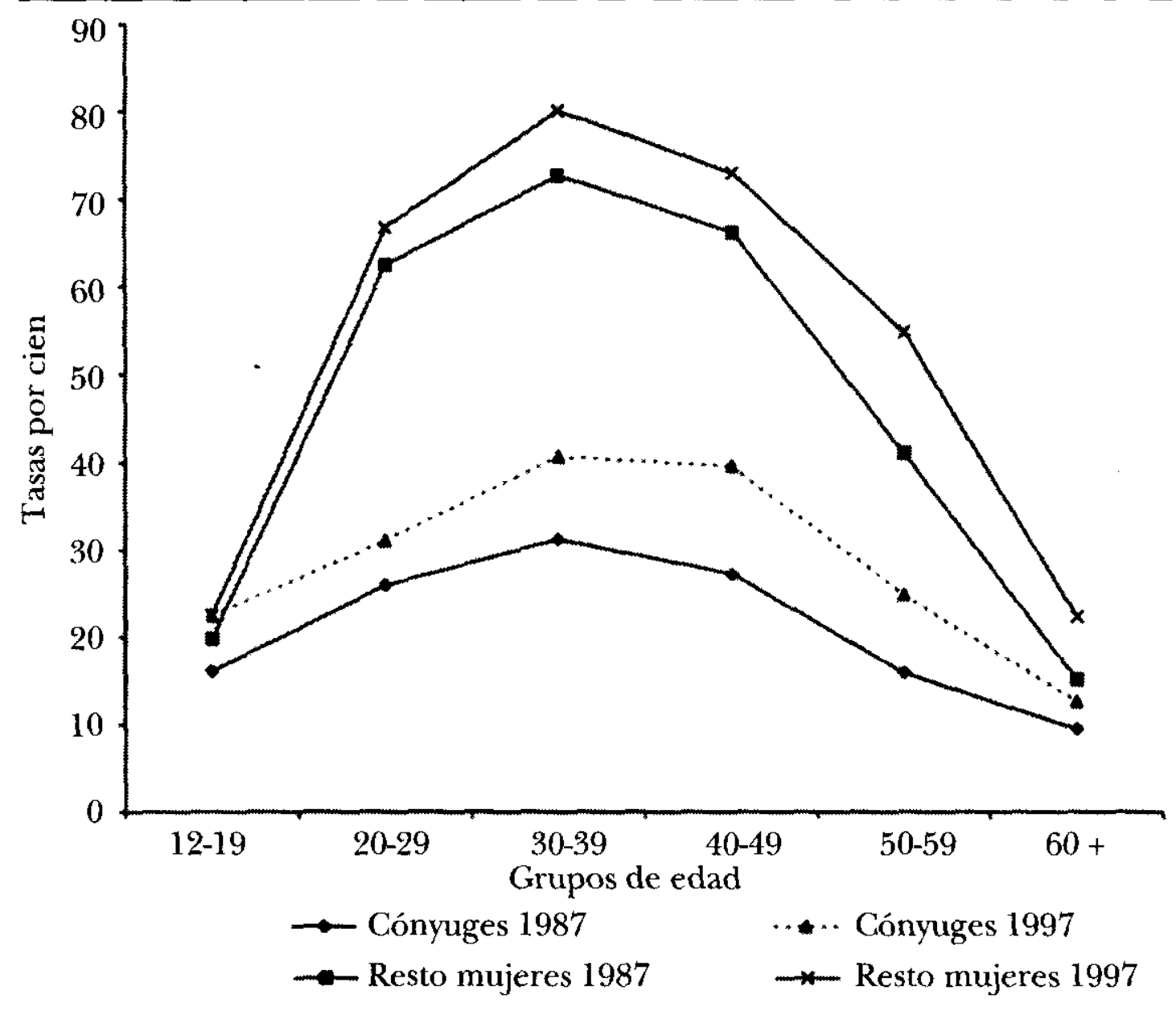

de estos hogares urbanos cuentan con una pareja al frente de la unidad doméstica, y esta cifra se mantuvo prácticamente inalterada durante el periodo. ${ }^{6}$

En los tres tipos de hogares encabezados por una pareja, el número relativo de hogares cuyo jefe era el único proveedor económico disminuyó significativamente en la última década. En 1997, 42\% de las cónyuges que vivían solas con su pareja eran económicamente activas al igual que el jefe del hogar, es decir un aumento de $37 \%$ en relación con la cifra de diez años antes. Este cambio fue aún más impresionante en los casos de los hogares nucleares con hijos: $52 \%$. Con

${ }^{6}$ No obstante que la mayoría de los hogares mexicanos continúan conformándose por el núcleo padres-hijos, la información de la ENEU revela un decremento absoluto de $3 \%$ de este tipo de hogares entre 1987 y 1997 . Este pequeño cambio tuvo como contraparte el aumento de los hogares de pareja sin hijos y de ambos tipos de hogares monoparentales. 
GUADRO 2

Distribución de los hogares según tipos de hogar y situación de empleo de las parejas (jefes de hogar y cónyuges). Áreas urbanas de México, 1987-1997* (porcentaje)

\begin{tabular}{|c|c|c|c|c|c|}
\hline $\begin{array}{l}\text { Tipos de hogary } \\
\text { situaciones de } \\
\text { empleo de las parejas }\end{array}$ & & & & 997 & $\begin{array}{r}\% \text { Cambio } \\
1987-1997\end{array}$ \\
\hline Total & 100.0 & & 100.0 & & \\
\hline $\begin{array}{l}\text { Pareja sin hijos } \\
\text { Sólo el jefe } \\
\text { Jefe y cónyuge } \\
\text { Sólo cónyuge } \\
\text { Ninguno }\end{array}$ & 5.2 & $\begin{array}{r}100.0 \\
66.2 \\
30.4 \\
2.9 \\
0.4\end{array}$ & 6.2 & $\begin{array}{r}100.0 \\
54.4 \\
41.5 \\
3.7 \\
0.5\end{array}$ & $\begin{array}{r}19.2 \\
-17.8 \\
36.5 \\
27.6 \\
25.0\end{array}$ \\
\hline $\begin{array}{l}\text { Pareja con hijos } \\
\text { Sólo el jefe } \\
\text { Jefe y cónyuge } \\
\text { Sólo cónyuge } \\
\text { Ninguno }\end{array}$ & 57.4 & $\begin{array}{r}100.0 \\
73.4 \\
21.8 \\
1.3 \\
3.5\end{array}$ & 54.1 & $\begin{array}{r}100.0 \\
61.4 \\
33.1 \\
1.5 \\
4.0\end{array}$ & $\begin{array}{r}-5.7 \\
-16.3 \\
51.8 \\
15.4 \\
14.3\end{array}$ \\
\hline $\begin{array}{l}\text { Pareja con hijos y otros } \\
\text { miembros } \\
\text { Sólo el jefe } \\
\text { Jefe y cónyuge } \\
\text { Sólo cónyuge } \\
\text { Ninguno }\end{array}$ & 13.4 & $\begin{array}{r}100.0 \\
64.7 \\
21.6 \\
2.5 \\
11.2\end{array}$ & 13.4 & $\begin{array}{r}100.0 \\
54.6 \\
29.1 \\
3.2 \\
13.1\end{array}$ & $\begin{array}{r}0.0 \\
-15.2 \\
34.7 \\
28.0 \\
17.0\end{array}$ \\
\hline Monoparental con hijos & 7.9 & & 9.0 & & 13.9 \\
\hline $\begin{array}{l}\text { Monoparental con hijos y otros } \\
\text { miembros }\end{array}$ & 5.4 & & 6.4 & & 18.5 \\
\hline Unipersonales & 3.4 & & 4.4 & & 29.4 \\
\hline Otros hogares & 7.3 & & 6.5 & & -11.0 \\
\hline
\end{tabular}

* Sólo se incluyen hogares con algún miembro económicamente activo.

Fuente: Encuesta Nacional de Empleo Urbano, abril-junio de 1987 y 1997, INEGI. Datos procesados por los autores.

ello, una de cada tres cónyuges pertenecientes a estos hogares eran económicamente activas en 1997. Finalmente, el aumento fue menor entre las parejas con hijos viviendo en hogares extendidos (muy posiblemente debido a que en dichos hogares es más probable que el número de potenciales trabajadores sea mayor). 


\section{Determinantes del trabajo extradoméstico de las cónyuges}

Debido a que la enorme mayoría de los jefes de hogar en edades potencialmente activas se encuentran en el mercado de trabajo, el examen de los determinantes del trabajo de ambos miembros de la pareja puede prácticamente ser analogado al examen de los determinantes del trabajo de las cónyuges. Estudios sobre los factores asociados a la propensión a trabajar de las cónyuges se han centrado fundamentalmente en la influencia de factores individuales (edad, nivel educativo, etc.), así como familiares (estructura familiar, nivel de ingresos del hogar, número y edad de los hijos, etc.). Sin embargo, como se señaló en la introducción, poca atención se ha prestado a la posible influencia de características referidas a la naturaleza y al tipo de empleo del jefe de hogar en la condición de actividad económica y en el tipo de ocupación de las cónyuges. El supuesto subyacente es que la naturaleza y las características del trabajo del jefe de hogar establecen tanto límites como posibilidades para el empleo de la cónyuge.

Con el objetivo de examinar la influencia neta de las características referidas a la mujer, al hogar y al esposo en las probabilidades de que la cónyuge trabaje, se estimaron dos modelos de regresión logística. La variable dependiente fue en todos los casos la probabilidad de que ambos miembros de la pareja trabajaran versus que cualquiera de ellos no lo hiciera (como se argumentó, esto equivale empíricamente a examinar la probabilidad de que la cónyuge trabaje). El primer modelo incluyó sólo variables referidas a la cónyuge y al hogar, mientras que el segundo incorpora información sobre la situación laboral del jefe (para mayores detalles véase el apéndice).

El cuadro 3 presenta los resultados de las regresiones logísticas. Las estimaciones del primer modelo no muestran resultados inesperados. La educación muestra una fuerte asociación positiva con la propensión a trabajar fuera del hogar de las cónyuges. El acceso a la educación universitaria incrementa notablemente estas posibilidades, aun controlando el contexto familiar y la edad de las cónyuges. ${ }^{7}$

La situación del hogar, y la presencia, número y edad de los hijos también establecen marcadas diferencias en la propensión al trabajo extradoméstico de las cónyuges. Parejas con hijos, en especial si éstos

${ }^{7}$ Sin efectuar controles, la proporción de parejas con ambos miembros trabajando se duplica (29 a 58\%) al comparar parejas con cónyuges que completaron la educación primaria y parejas con cónyuges que accedieron a algún año de enseñanza universitaria. 
son menores de seis años, presentan pocas posibilidades para que las cónyuges participen en la fuerza de trabajo. Visto de otra forma, las parejas sin hijos son aquéllas entre las cuales es más probable encontrar a ambos miembros trabajando.

Los resultados muestran una relación interesante sobre las restricciones familiares. Si bien la presencia de hijos pequeños en el hogar reduce significativamente las propensiones de trabajar de las cónyuges, éstas se incrementan en forma notable si en el hogar vive otra mujer mayor de 14 años, económicamente inactiva. Este hallazgo permite argumentar sobre la existencia de un menor costo de oportunidad para las cónyuges de salir a trabajar fuera del hogar, en aquellos casos en que éstas cuenten con el apoyo de mujeres adultas inactivas que puedan hacerse cargo del cuidado de los hijos y de otras tareas domésticas.

El segundo modelo incorpora las variables referidas al jefe del hogar. Un primer hallazgo importante es que la inclusión de esta información mejoró significativamente el ajuste del modelo. ${ }^{8}$ Esto significa que, una vez controlados los factores individuales y del hogar, las características laborales de los jefes son de gran relevancia en la predicción del comportamiento económico de las cónyuges.

La propensión de las cónyuges a participar en el mercado de trabajo es $38 \%$ superior en los casos en que el jefe de hogar desempeña un trabajo no asalariado que en aquellos en que lo hace bajo una relación salarial (obtenga o no beneficios laborales). Podrían argumentarse tres interpretaciones a esta relación. Una se relaciona con la mayor inestabilidad de las actividades no asalariadas o informales. La irregularidad de los ingresos en este tipo de actividades económicas muy probablemente incentive el trabajo de la cónyuge como un medio para la reducción de la incertidumbre económica. ${ }^{9}$

La segunda tiene que ver con la flexibilidad que ofrece el trabajo independiente para el manejo del tiempo, lo cual posibilita que el jefe del hogar pueda apoyar algunas actividades del hogar o del cuidado de los hijos, en el caso de que la cónyuge cuente con una buena oportunidad de producir ingresos. Finalmente, y como se documenta

${ }^{8}$ El mejor ajuste del modelo se manifiesta en la prueba de significancia estadística de la diferencia de los -2 Log likelihood relativa al cambio en los grados de libertad de los modelos. La diferencia entre ambos modelos es significativa al .999 según la distribución $\chi^{2}$.

${ }^{9} \mathrm{Si}$ bien el modelo estadístico toma en consideración el nivel de ingresos del jefe, en éste no se controla la estabilidad de los mismos a través del tiempo. 


\section{CUADRO 3}

Resultados de regresión logística de los determinantes individuales y del hogar de que el jefe y la cónyuge participen en actividades económicas. Áreas urbanas de México, 1997

\begin{tabular}{|c|c|c|c|c|}
\hline \multirow[b]{2}{*}{ Variables independientes } & \multicolumn{2}{|c|}{ Modelo 1} & \multicolumn{2}{|c|}{ Modelo 2} \\
\hline & Coeficiente & $\begin{array}{l}\text { Razón de } \\
\text { momios }\end{array}$ & $\begin{array}{lr} & R \\
\text { Coeficiente } & ?\end{array}$ & $\begin{array}{l}\text { Razón de } \\
\text { momios }\end{array}$ \\
\hline Constante & $0.761^{* * *}$ & & $1.049^{* * *}$ & \\
\hline \multicolumn{5}{|l|}{$\begin{array}{l}\text { Presencia de hijo pequeño } \\
\text { y adulta inactiva en el hogar }\end{array}$} \\
\hline Sí hijo pequeño, no adulta & $-0.420 * * *$ & 0.66 & $-0.427 * * *$ & 0.65 \\
\hline Sí hijo pequeño, sí adulta & $-0.212 * * *$ & 0.81 & $-0.218^{* * *}$ & 0.80 \\
\hline $\begin{array}{l}\text { No hijo pequeño, sí adulta } \\
\text { No hijo pequeño, no adulta }\end{array}$ & $-0.239 * * *$ & 0.79 & $-0.235^{* * *}$ & 0.79 \\
\hline \multicolumn{5}{|l|}{ Número de hijos } \\
\hline $\begin{array}{l}\text { Ninguno } \\
\text { De } 1 \text { a } 2 \text { hijos }\end{array}$ & $0.195^{* * *}$ & 1.22 & $0.179 * * *$ & 1.20 \\
\hline 3 y más & $-0.136^{* * *}$ & 0.87 & $-0.1308 * * *$ & 0.88 \\
\hline \multicolumn{5}{|l|}{ Educación cónyuge } \\
\hline Menos de primaria completa & $-1.229 * * *$ & 0.29 & $-1.459 * * *$ & 0.23 \\
\hline Primaria completa & $-1.250 * * *$ & 0.29 & $-1.428 * * *$ & 0.24 \\
\hline $\begin{array}{l}\text { Algún año de secundaria } \\
\text { o preparatoria }\end{array}$ & $-0.924 * * *$ & 0.40 & $-1.035^{* * *}$ & 0.36 \\
\hline Algún año de universidad & & & & \\
\hline \multicolumn{5}{|l|}{ Edad cónyuge } \\
\hline $\begin{array}{l}\text { Menos de } 31 \text { años } \\
31-50 \text { años }\end{array}$ & $-0.228 * * *$ & 0.80 & $-0.230^{* *}$ & 0.79 \\
\hline Más de 50 años & $-0.737 * * *$ & 0.48 & $-0.799 * * *$ & 0.45 \\
\hline \multicolumn{5}{|l|}{ Inserción laboral jefe } \\
\hline Asalariado sin beneficios & & & 0.013 & 1.01 \\
\hline No asalariado & & & $0.323^{* * *}$ & 1.38 \\
\hline Ingresos del jefe & & & $-0.00004^{* * *}$ & \\
\hline \multicolumn{5}{|l|}{ Horas trabajadas por el jefe } \\
\hline \multicolumn{5}{|l|}{ Menos de 40 horas semanales } \\
\hline 40 o más horas semanales & & & $-0.155^{* * *}$ & 0.86 \\
\hline \multicolumn{5}{|l|}{ Número de casos: 21464} \\
\hline - 2 Log Likelihood & 26695 & & 26493 & \\
\hline
\end{tabular}

Nota: ***p.<.001, **p.<.01, *p.<.05.

Fuente: Encuesta Nacional de Empleo Urbano, abril-junio de 1997, INEGI. Datos procesados por los autores. 
más adelante, el trabajo independiente del jefe en actividades comerciales o de pequeños talleres genera oportunidades de empleo para las cónyuges en la forma de trabajo familiar no remunerado.

Los argumentos anteriores se refuerzan en gran medida al observar el efecto del número de horas trabajadas por el jefe del hogar: las posibilidades de que una cónyuge forme parte de la fuerza de trabajo se incrementa cuando el jefe del hogar labora menos de 40 horas a la semana. Así pues, la mayor participación económica de las cónyuges puede estar fuertemente asociada a las presiones económicas derivadas de una jornada laboral reducida de los jefes de hogar, y a la vez relacionada con las posibilidades que esta condición laboral abre para que los jefes puedan cubrir a las cónyuges en algunas actividades domésticas. Un análisis detallado de la división sexual del trabajo de las parejas, así como del. proceso de toma de decisiones que la conforman, permitirían evaluar empíricamente estas hipótesis no necesariamente excluyentes.

\section{Cambios en las condiciones laborales de cónyuges y jefes}

¿En qué medida el conocido deterioro de las condiciones laborales de los hombres y la creciente demanda de trabajo femenino ha significado la búsqueda de una complementariedad laboral entre jefes y cónyuges, en donde los primeros buscan maximizar sus ingresos en cualquier tipo de actividad económica (aun a costa de perder beneficios laborales), y las segundas buscan empleos asalariados que aunque mal remunerados proveen acceso a seguridad social, especialmente servicios de salud?

Una respuesta positiva a esta pregunta encuentra poca evidencia empírica: tanto los jefes como las cónyuges presentan un deterioro significativo de sus condiciones laborales. Mientras que en 1987, $31 \%$ de las parejas tenían empleos asalariados con beneficios laborales (salud, aguinaldo y prima vacacional), sólo $24 \%$ los tenía diez años más tarde (véase el cuadro 4). El porcentaje de parejas en que la cónyuge contaba con beneficios laborales y el jefe no, se mantuvo prácticamente inalterado. A diferencia de las cónyuges cuyo detrimento laboral tuvo como contrapartida un incremento en el empleo asalariado sin beneficios, los jefes de hogares mostraron un ascenso en el trabajo como patrones o autoempleados.

En términos del bienestar y seguridad de las parejas trabajadoras, el deterioro laboral se manifiesta claramente en el hecho de que a pe- 
CUADRO 4

Distribución de las parejas económicamente activas según posición en la ocupación del jefe de hogar y la cónyuge. Área Metropolitana de la Ciudad de México, 1987 y 1997

\begin{tabular}{|c|c|c|c|c|c|}
\hline \multirow[b]{2}{*}{ Cónyuges } & \multicolumn{5}{|c|}{ Jefes de hogar } \\
\hline & $\begin{array}{c}\text { Patrones } \\
\text { y cuenta } \\
\text { propia }\end{array}$ & $\begin{array}{c}\text { Asalariados } \\
\text { con } \\
\text { beneficios }\end{array}$ & $\begin{array}{c}\text { Asalariados } \\
\text { sin } \\
\text { beneficios }\end{array}$ & $\begin{array}{c}\text { No } \\
\text { remunerados }\end{array}$ & Total \\
\hline \multicolumn{6}{|c|}{$\begin{array}{l}\text { Patronas y cuenta } \\
\text { propia }\end{array}$} \\
\hline 1987 & 7.9 & 8.0 & 5.6 & 0.5 & 22.0 \\
\hline 1997 & 9.3 & 8.1 & 5.8 & 1.1 & 24.3 \\
\hline \multicolumn{6}{|c|}{$\begin{array}{l}\text { Asalariadas con } \\
\text { beneficios }\end{array}$} \\
\hline 1987 & 8.6 & 30.9 & 6.9 & 0.0 & 46.4 \\
\hline 1997 & 8.8 & 23.9 & 6.4 & 0.0 & 39.0 \\
\hline \multicolumn{6}{|c|}{$\begin{array}{l}\text { Asalariadas sin } \\
\text { beneficios }\end{array}$} \\
\hline 1987 & 4.9 & 7.1 & 6.4 & 0.1 & 18.5 \\
\hline 1997 & 6.6 & 8.2 & 7.8 & 0.1 & 22.7 \\
\hline \multicolumn{6}{|c|}{ No remuneradas } \\
\hline 1987 & 11.7 & 0.8 & 0.6 & 0.0 & 13.1 \\
\hline 1997 & 12.4 & 0.8 & 0.7 & 0.1 & 14.0 \\
\hline \multicolumn{6}{|l|}{ Total } \\
\hline 1987 & 33.2 & 46.7 & 19.5 & 0.6 & $100.0 \%$ \\
\hline 1997 & 37.0 & 41.0 & 20.7 & 1.3 & $100.0 \%$ \\
\hline
\end{tabular}

Fuente: Encuesta Nacional de Empleo Urbano, abril-junio de 1987 y 1997, INEGI. Datos procesados por los autores.

sar del incremento en el trabajo femenino, el número relativo de parejas en que ambos miembros no cuentan con beneficios laborales se incrementó de 38 a 44 por ciento.

La información permite además apreciar un aspecto importante de la complementariedad entre los jefes y las cónyuges: después de la combinación ambos trabajando como asalariados con beneficios laborales, es la combinación jefe patrón o trabajador por cuenta propia y cónyuge trabajadora no remunerada la que concentra un mayor número de parejas económicamente activas. Este hallazgo es interesante porque pone en evidencia la centralidad que tiene el trabajo familiar no remunerado como alternativa dé empleo para mujeres con de- 
mandas de tipo domésticas en el México urbano. Asimismo evidencia el carácter familiar de la actividad económica en pequeña escala ya que, en 1987, un tercio de los jefes patrones y por cuenta propia utilizaron en su actividad económica trabajo familiar no remunerado.

Cabe preguntarse sin embargo, ¿en qué medida el deterioro de las condiciones laborales de las parejas fue, durante el periodo 19871997, consecuencia del crecimiento de las tasas de participación de mujeres en edades adultas avanzadas, es decir, de cohortes de mujeres con niveles educativos promedio más bajos que aquellas más jóvenes, y además muy probablemente con trayectorias laborales muy irregulares? El cuadro 5 permite verificar qué deterioro laboral tuvo lugar entre parejas que se encontraban transitando diferentes etapas del ciclo de vida familiar, medido esto último de manera burda mediante la edad del jefe del hogar.

Más aún, los datos sugieren que fueron las parejas más jóvenes las que padecieron los mayores cambios en sus condiciones laborales durante la última década, pues el porcentaje de parejas en que ambos trabajaban como asalariados con beneficios diminuyó en diez puntos en números absolutos (pasando de 44 a $34 \%$ de las parejas jóvenes). Esta tendencia puede observarse también entre las parejas cuyos jefes tenían 31-49 años de edad, sin embargo, el descenso no fue tan marcado.

Entre parejas en un ciclo de vida más avanzado (o sea con jefes de 50 años o más) se observa la clara importancia relativa de las actividades económicas familiares. Tanto antes como ahora, más de dos de cada 10 parejas trabajadoras se compone de un jefe que trabaja por su cuenta o patrón y una cónyuge que es trabajadora familiar no remunerada. Entre estas parejas el deterioro de sus condiciones laborales no ha sido tan pronunciado debido en gran parte a que sus niveles de trabajo asalariado y de beneficios laborales eran ya de por sí bajos en 1987.

\section{Cambios en los aportes económicos de las cónyuges}

El aumento en la participación económica de las cónyuges ha implicado obviamente un decremento del número relativo de mujeres que dependen totalmente de los ingresos generados por sus maridos. Como recién se mostró, el porcentaje de parejas en que las mujeres dependen en forma exclusiva de los ingresos de sus maridos ha dismi- 
CUADRO 5

Distribución de las parejas económicamente activas según posición en la ocupación del jefe de hogar y la cónyuge y edad del jefe de hogar. Área Metropolitana de la Ciudad de México, 1987 y 1997

\begin{tabular}{|c|c|c|c|c|c|c|c|c|}
\hline \multirow[b]{3}{*}{ Cónyuges } & \multicolumn{8}{|c|}{ Jefes de hogar } \\
\hline & \multicolumn{4}{|c|}{1987} & \multicolumn{4}{|c|}{1997} \\
\hline & $\begin{array}{c}\text { Patrones } \\
\text { cuenta } \\
\text { propia }\end{array}$ & $\begin{array}{c}\text { Asalar. } \\
\text { con } \\
\text { benef. }\end{array}$ & $\begin{array}{c}\text { Asalar. } \\
\text { sin } \\
\text { benef. }\end{array}$ & $\begin{array}{l}\text { No } \\
\text { remun. Tolal }\end{array}$ & $\begin{array}{c}\text { Patrones } \\
\text { cuenta } \\
\text { propia }\end{array}$ & $\begin{array}{c}\text { Asalar. } \\
\text { con } \\
\text { benef. }\end{array}$ & $\begin{array}{c}\text { Asalar. } \\
\text { sin } \\
\text { benef. }\end{array}$ & Nomun. Total \\
\hline & \multicolumn{8}{|c|}{ Jefes de hogar <31 años } \\
\hline Patronas y cuenta propia & 3.2 & 5.1 & 3.4 & 0.0 & 4.5 & 5.7 & 4.3 & 0.4 \\
\hline Asalariadas con beneficios & 7.2 & 43.8 & 12.1 & 0.0 & 7.0 & 33.9 & 8.5 & 0.0 \\
\hline Asalariadas sin beneficios & 3.5 & 7.9 & 6.7 & 0.1 & 3.5 & 11.4 & 11.4 & 0.0 \\
\hline No remuneradas & 5.7 & 0.6 & 0.7 & 0.0 & 7.0 & 0.9 & 1.5 & 0.0 \\
\hline \multirow[t]{2}{*}{ Total } & \multicolumn{7}{|c|}{100.0} & \multirow[t]{2}{*}{100.0} \\
\hline & \multicolumn{7}{|c|}{ Jefes de hogar $31-49$ años } & \\
\hline Patronas y cụenta propia & 7.7 & 9.2 & 6.0 & 0.4 & 8.7 & 9.3 & 6.1 & 0.8 \\
\hline Asalariadas con beneficios & 9.7 & 29.9 & 5.5 & 0.0 & 9.8 & 24.1 & 6.6 & 0.0 \\
\hline Asalariadas sin beneficios & 4.9 & 7.5 & 6.3 & 0.0 & 6.8 & 8.1 & 7.1 & 0.1 \\
\hline No remuneradas & 11.5 & 0.9 & 0.5 & 0.0 & 11.3 & 0.8 & 0.5 & 0.0 \\
\hline \multirow[t]{2}{*}{ Total } & \multicolumn{7}{|c|}{100.0} & \multirow[t]{2}{*}{100.0} \\
\hline & \multicolumn{7}{|c|}{ Jefes de hogar 50 años y más } & \\
\hline Patronas y cuenta propia & 17.8 & 7.4 & 8 & 2.1 & 16.9 & 6.3 & 6.7 & 3.1 \\
\hline Asalariadas con beneficios & 6.2 & 11.3 & 3.8 & 0 & 7.1 & 11.4 & 3.3 & 0.1 \\
\hline Asalariadas sin beneficios & 7.7 & 3.9 & 6.3 & 0.3 & 7.1 & 11.4 & 3.3 & 0.1 \\
\hline No remuneradas & 23.7 & 0.5 & 0.9 & 0.2 & 22.6 & 0.7 & 0.7 & 0.4 \\
\hline Total & & & & 100.0 & & & & 100.0 \\
\hline
\end{tabular}

Fuente: Encuesta Nacional de Empleo Urbano, abril-junio de 1987 y 1997, INEGI. Datos procesados por los autores.

nuido significativamente. Una interrogante que surge en el contexto de la creciente participación de las cónyuges en actividades económicas es si el aporte relativo de uno y otro miembro de la pareja ha variado de manera notable, o en otras palabras, si el incremento del trabajo de las cónyuges ha venido acompañado también por una modificación en su contribución económica vis a vis la del jefe.

Antes de presentar los resultados, es importante recordar que a pesar de que nuestro análisis de la contribución económica de las cónyuges no permite asumir ninguna forma particular de control y asignación de recursos dentro de la unidad doméstica, partimos de la base de que el nivel de ingreso aportado por las mujeres al ingreso de la pareja está asociado positivamente a su autonomía y poder de decisión (Oppenheim Mason, 1996; Blumberg 1991). 
Si bien el aumento de parejas económicamente activas es un dato alentador para las relaciones de género en México, los datos muestran que los niveles de dependencia económica de las cónyuges continúan siendo altos, especialmente al comparar éstos con la experiencia de los países más desarrollados. Así, por ejemplo, los niveles de dependencia económica de las mujeres residentes en las áreas urbanas del país en 1997 son muy similares a los observados en Estados Unidos en 1950 , cuando $68 \%$ de las cónyuges dependía totalmente de los ingresos del esposo (Sorensen y McLanahan, 1987).

Aunque más cónyuges trabajaban en 1997 que en 1987, la evolución de la relación de ingresos cónyuges/jefes no presenta un panorama tan optimista. Los aportes de ambos miembros a los ingresos de las parejas no variaron significativamente entre estas fechas (véase la gráfica 2).

\section{GRÁFICA 2}

\section{Proporción del ingreso total de la pareja que es contribuido por la mujer}

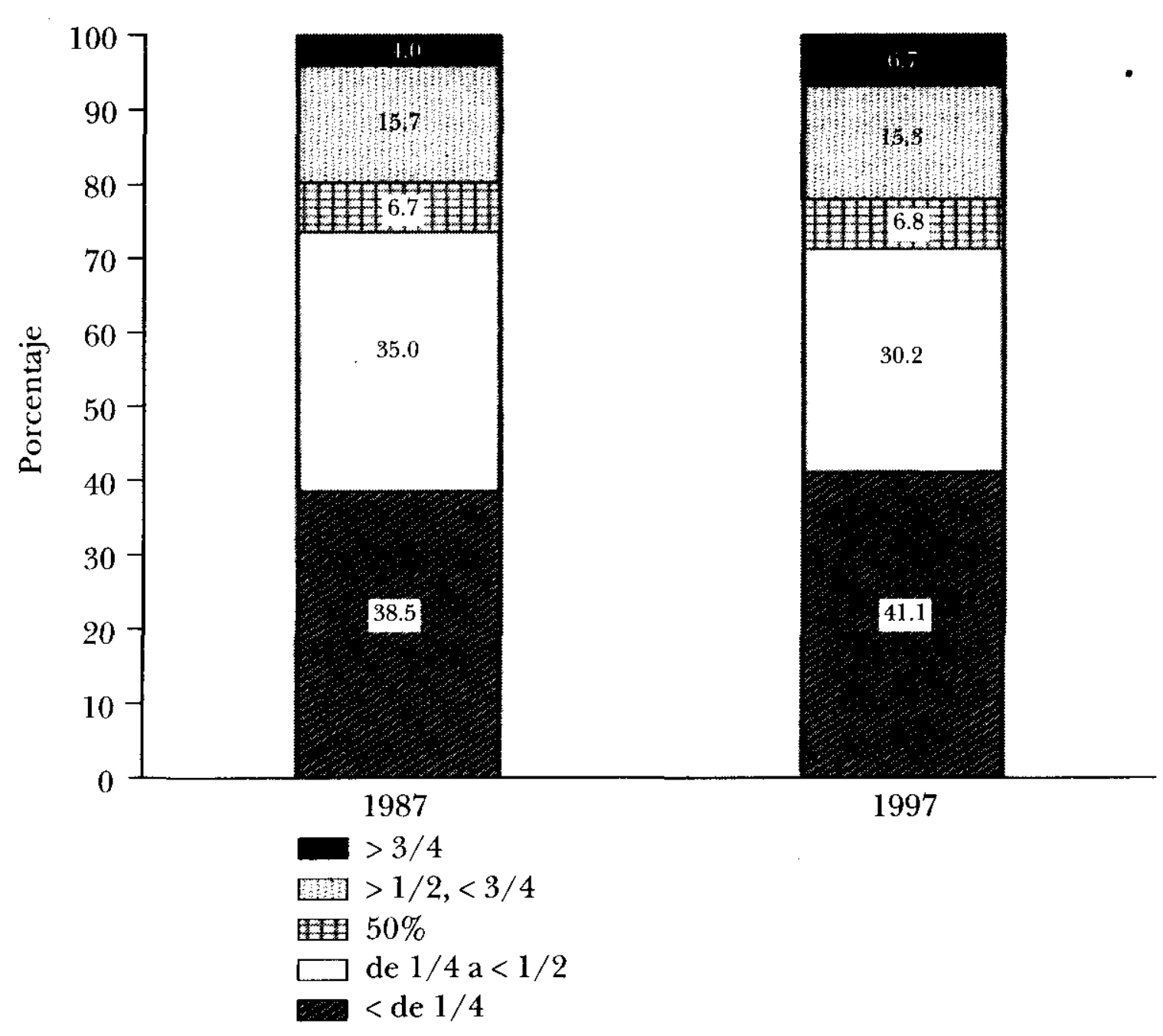


La enorme mayoría de las cónyuges trabajadoras continuaba generando ingresos sustancialmente inferiores a los de sus maridos en 1997. En 1987, 74\% de las cónyuges percibían ingresos inferiores a los del jefe del hogar. Esta cifra disminuyó ligeramente (71\%) una década más tarde. Más aún, tanto en 1987 como en 1997, los ingresos de las mujeres constituían menos de la mitad de los correspondientes a sus esposos en $40 \%$ de las parejas.

Si bien las mujeres en general continúan generando ingresos muy inferiores a los de sus cónyuges, es importante señalar que una proporción no despreciable de ellas (una de cada cinco) obtiene ingresos superiores. Más aún, la proporción de las mujeres que ganan el doble o más que sus parejas aumentó durante el periodo 1987-1997 (de 4 a 7 por ciento).

La relación entre los ingresos de jefes y cónyuges varía de acuerdo con la etapa de consolidación de la familia. Utilizando nuevamente la edad del jefe de hogar como indicador se puede observar (véase el cuadro 6) que es durante las etapas iniciales de consolidación de la familia cuando la relación de ingresos entre jefes y cónyuges es menos desigual. Si las cónyuges son jóvenes y se encuentran trabajando, es mucho más probable que lo hagan de tiempo completo, en contraste con aquellas que tienen mayores demandas de tipo doméstico, y que por lo tanto generan ingresos, si bien más bajos, menos desiguales que sus maridos. Por ejemplo, en 1997, un tercio de las cónyuges cuyos jefes tenían hasta 30 años de edad ganaban menos de la mitad que sus maridos, mientras que alrededor de la mitad cumplían con la misma condición entre aquéllas cuyo jefe era mayor de 50 años.

En cuanto a la influencia de factores extrafamiliares, la brecha de ingresos de acuerdo con la etapa de consolidación de la familia puede deberse a las diferencias en la retribución a la experiencia laboral entre miembros de la pareja. Puede argumentarse que en el caso de las parejas jóvenes, las diferencias en los premios recibidos debido a la experiencia laboral son prácticamente nulas, mientras que entre aquellas en edades más avanzadas los premios en favor de los varones son muy superiores debido a que ellos permanecen por tiempos más prolongados en la fuerza de trabajo.

\section{Determinantes de la desigualdad de ingresos entre jefes y cónyuges}

Los factores que explican la diferencia en los ingresos entre el jefe y su cónyuge son numerosos. Algunos de éstos se vinculan indudable- 


\section{GUADRO 6}

Distribución de las parejas económicamente activas según grado de dependencia económica por concepto de trabajo y edad del jefe de hogar. Áreas urbanas de México, 1987 y 1997 (porcentaje)

\begin{tabular}{|c|c|c|c|c|c|c|}
\hline \multirow{2}{*}{$\begin{array}{l}\text { Proporción de ingresos } \\
\text { aportados por ambos } \\
\text { miembros de la pareja }\end{array}$} & \multicolumn{2}{|c|}{$\begin{array}{c}\text { Jefe de hogar } \\
\text { menor de } 31 \text { Años }\end{array}$} & \multicolumn{2}{|c|}{$\begin{array}{l}\text { Jefe de hogar } \\
31-50 \text { años }\end{array}$} & \multicolumn{2}{|c|}{$\begin{array}{c}\text { Jefe de hogar } \\
\text { mayor de } 50 \text { años }\end{array}$} \\
\hline & 1987 & 1997 & $\overline{1987}$ & 1997 & 1987 & 1997 \\
\hline Total & 100.0 & 100.0 & 100.0 & 100.0 & 100.0 & 100.0 \\
\hline $\begin{array}{l}\text { Cónyuge contribuye menos } \\
\text { de } 50 \% \text { de lo que gana el } \\
\text { jefe del hogar }\end{array}$ & 27.3 & 32.8 & 40.7 & 42.0 & 49.5 & 48.3 \\
\hline $\begin{array}{l}\text { Cónyuge contribuye entre } \\
50-99 \% \text { de lo que gana el } \\
\text { jefe del hogar }\end{array}$ & 39.5 & 36.3 & 35.4 & 30.0 & 25.2 & 23.2 \\
\hline $\begin{array}{l}\text { Cónyuge y jefe contribuyen } \\
\text { igual }\end{array}$ & 8.7 & 8.2 & 6.0 & 6.4 & 6.2 & 6.1 \\
\hline $\begin{array}{l}\text { Jefe de hogar contribuye } \\
\text { menos de } 50 \% \text { de lo que } \\
\text { gana la cónyuge }\end{array}$ & 3.2 & 4.7 & 3.8 & 6.3 & 6.7 & 10.5 \\
\hline $\begin{array}{l}\text { Jefe de hogar contribuye } \\
\text { entre } 50-99 \% \text { de lo que } \\
\text { gana la cónyuge }\end{array}$ & 21.3 & 18.0 & 14.1 & 15.2 & 12.4 & 11.9 \\
\hline
\end{tabular}

Fuente: Encuesta Nacional de Empleo Urbano, 1987 y 1997 (segundo trimestre), INEGI. Datos procesados por los autores.

mente con sus diferencias en capital humano (educación y experiencia). Otras se relacionan con la discriminación laboral producto de retribuir diferencialmente a mujeres y varones aun cuando éstos desempeñan ocupaciones de similar calificación. Como señalan Sorensen y McLanahan (1987) para el contexto de Estados Unidos, la discriminación laboral por sexo cumple también un papel importante en la determinación de las diferencias de ingresos entre miembros de las parejas. Asimismo, la segregación ocupacional cumple un rol importante en los diferenciales salariales entre varones y mujeres (England, 1992).

Las diferencias en los ingresos entre miembros de las parejas podría también vincularse con los arreglos que se establecen entre carreras laborales de jefes y cónyuges. Como lo sugerimos anteriormente, es posible que la naturaleza y las características del empleo de la 
cónyuge no estén únicamente determinadas por la demanda de trabajo, las características individuales y las preferencias de las mujeres, sino también por arreglos laborales entre jefes y cónyuges. Estos arreglos laborales están determinados en gran medida por la división del trabajo por género. Las características y condiciones de trabajo de uno de los miembros no son independientes de las características y condiciones de trabajo del otro. Así por ejemplo, el número de horas trabajadas, la restricción o la flexibilidad en horarios o días de trabajo en el empleo del jefe establecen límites a su posible contribución a las tareas del hogar. De la misma forma, el acceso del jefe a beneficios laborales y su nivel de ingreso afecta no sólo la propensión a trabajar de las cónyuges sino también el tipo de empleo que realiza. De esta forma, si el empleo del jefe le requiere ausentarse del hogar por gran parte del día y no brinda flexibilidad alguna, es de esperarse que la cónyuge trabaje por un número reducido de horas y en ocupaciones que provean cierta flexibilidad. En estas condiciones, es fácil suponer que las cónyuges producirán ingresos muy inferiores a los de su pareja. Debido a que en la mayoría de los casos las responsabilidades domésticas recaen en las mujeres, es muy probable que tos arreglos laborales de las parejas tengan como consecuencia una menor percepción de ingresos para las mujeres.

Si bien menos frecuente, en el caso de mujeres con carreras laborales estables y con un alto compromiso en su trabajo, es posible que la relación sea inversa. ${ }^{10}$ De existir tal relación, la contribución relativa de cada miembro estaría vinculada con dichos arreglos (no necesariamente consensuales), con las oportunidades de empleo disponibles en el mercado de trabajo para ambos miembros de la pareja en un momento determinado, y con la posibilidad de contar con apoyo para la realización de actividades domésticas.

Poco se conoce sobre los determinantes de las diferencias en los aportes económicos de cónyuges y jefes, especialmente en el caso de México. Los estudios referidos a los ingresos de las mujeres se han centrado en la evolución de la desigualdad de ingresos por sexos (Es-

${ }^{10}$ Por ejemplo, Cerrutti (1997), en sus entrevistas en profundidad con mujeres residentes en Buenos Aires, encontró que las mujeres que tenían una alta estabilidad en empleos formales con beneficios laborales, en general formaban parejas con esposos que trabajaban en forma independiente y con una mayor flexibilidad en sus horarios. La entrada de un sueldo seguro por parte de la mujer aminoraba la incertidumbre económica generada por las trayectorias laborales inestables de sus maridos. 
trella y Zenteno, 1998), y en los determinantes de dicha desigualdad (Selby et al., 1996; Cerrutti, 1997). La evidencia empírica señala que, entre 1988 y 1994, la desigualdad en los ingresos medianos de hombres y mujeres se incrementó en casi dos terceras partes de las áreas metropolitanas más importantes de México (Estrella y Zenteno, 1998). Esta desigualdad coincide con la creciente incorporación de mujeres casadas al mercado laboral.

En cuanto a los diferenciales de ingresos, se ha observado que en el mismo nivel de capital humano y de características laborales, las mujeres de la Ciudad de México obtienen ingresos inferiores en 15\% a los de sus pares masculinos (Cerrutti, 1997). Asimismo, Selby et al. (1996) han estimado que sólo $50 \%$ de la brecha de ingresos entre varones y mujeres en los centros urbanos de la Ciudad de México, Guadalajara, Monterrey y Tijuana se debe a diferencias en el capital humano y en la experiencia laboral, por lo que el residual puede ser interpretado como el efecto de la discriminación por sexo que existe en el mercado de trabajo.

En esta sección se examinan, de manera exploratoria, algunos factores relacionados con las aportaciones económicas relativas de jefes y cónyuges. La parte inicial presenta un análisis descriptivo de esta relación en función de características referidas a la cónyuge, al jefe y a la relación entre ambos, y posteriormente esta discusión se extiende a un análisis estadístico multivariado prediciendo las aportaciones de las cónyuges a los ingresos de las parejas. El análisis se centra únicamente en parejas en que ambos miembros eran económicamente activos y especificaron el monto de ingresos recibidos en la ocupación principal.

El cuadro 7 muestra la relación de ingresos relativos entre las cónyuges y los jefes con relación a varias características individuales y laborales. Como puede observarse, la proporción de mujeres que generan ingresos inferiores a los de sus maridos disminuye con el nivel educativo, en especial entre los grupos de mujeres con mayor educación (es decir quienes alcanzaron el nivel universitario). Así, por ejemplo, entre las mujeres con menor educación formal (menos de primaria completa), una quinta parte genera ingresos que son iguales o superiores a los de su marido, mientras que entre aquellas que al: canzaron algún año de enseñanza universitaria, dicha proporción asciende a 41 por ciento.

Las diferencias que establece la educación pueden deberse a dos razones principales. La primera es que las mujeres con muy baja edu- 


\section{CUADRO 7}

Relación de ingresos cónyuge/jefe según variables seleccionadas. Áreas urbanas de México, 1997*

\begin{tabular}{|c|c|c|c|c|}
\hline \multirow[b]{2}{*}{ Variables seleccionadas } & \multicolumn{4}{|c|}{ Ingresos cónyuge en relación con los del jefe } \\
\hline & Menores & Iguales & Mayores & Total \\
\hline \multicolumn{5}{|l|}{ Educación } \\
\hline Menos de primaria completa & 76.6 & 5.9 & 17.5 & 100.0 \\
\hline Primaria completa & 73.5 & 9.1 & 17.4 & 100.0 \\
\hline \multicolumn{5}{|l|}{ Algún año de secundaria } \\
\hline o preparatoria & 66.2 & 8.3 & 25.5 & 100.0 \\
\hline Algún año de universidad & 59.4 & 13.1 & 27.5 & 100.0 \\
\hline \multicolumn{5}{|l|}{ Edad de la cónyuge } \\
\hline Menos de 31 años & 71.2 & 8.8 & 20.0 & 100.0 \\
\hline 31 a 50 años & 66.8 & 9.4 & 23.8 & 100.0 \\
\hline Más de 50 años & 68.4 & 4.8 & 26.8 & 100.0 \\
\hline \multicolumn{5}{|l|}{ Horas trabajadas } \\
\hline Menos de 20 horas & 86.2 & 3.3 & 10.5 & 100.0 \\
\hline de 20 a 39 & 67.5 & 8.3 & 24.2 & 100.0 \\
\hline 40 horas y más & 58.8 & 12.5 & 28.7 & 100.0 \\
\hline \multicolumn{5}{|l|}{ Inserción laboral } \\
\hline Asalariada con beneficios & 56.3 & 12.9 & 30.8 & 100.0 \\
\hline Asalariada sin beneficios & 77.8 & 6.3 & 15.9 & 100.0 \\
\hline No asalariada & 78.8 & 4.7 & 16.5 & 100.0 \\
\hline \multicolumn{5}{|l|}{$\begin{array}{l}\text { Relación de educación } \\
\text { cónyuge-jefe }\end{array}$} \\
\hline Cónyuge menor educación & 75.0 & 7.8 & 17.2 & 100.0 \\
\hline Ambos la misma educación & 66.7 & 10.2 & 23.1 & 100.0 \\
\hline Cónyuge más educación & 59.1 & 8.1 & 32.8 & 100.0 \\
\hline \multicolumn{5}{|l|}{ Horas trabajadas por el jefe } \\
\hline Menos de 20 & 63.5 & 4.5 & 32.0 & 100.0 \\
\hline 20-39 horas & 57.8 & 12.7 & 29.5 & 100.0 \\
\hline 40 y más horas & 70.9 & 8.5 & 20.6 & 100.0 \\
\hline
\end{tabular}

* La información del cuadro no incluye a los trabajadores(as) no remunerados. Fuente: Encuesta Nacional de Empleo Urbano, 1987 y 1997 (segundo trimestre), INEGI. Datos procesados por los autores.

cación tienden a trabajar menos horas que aquellas que tienen mayor educación. Por lo tanto la diferencia en las horas trabajadas por cónyuges y jefes explicaría los contrastes según el nivel educativo. La segunda es que las mujeres tienden a casarse con hombres que poseen niveles de educación formal superiores a los de ellas. Este argumento encuentra sostén empírico en los datos de la ENEU, pues sólo $18 \%$ de las cónyuges cuenta con más educación formal que sus esposos. Esto 
muestra claramente que no es sólo el nivel absoluto de educación lo que explica las diferencias de ingresos entre cónyuges y jefes, sino también el nivel relativo entre los miembros de la pareja. Como puede observarse en el cuadro 7, las mujeres con mayor educación que los jefes son más susceptibles de producir mayores ingresos.

Otro factor crucial en la determinación del aporte económico relativo de las cónyuges es el número de horas trabajadas. Como es de esperarse, aquellas mujeres que trabajan pocas horas a la semana tienen una mayor probabilidad de generar ingresos inferiores a los de sus maridos, mientras que las que trabajan tiempo completo contribuyen prácticamente en igual medida que los jefes. Mientras que $86 \%$ de las cónyuges que trabajan menos de 20 horas a la semana contribuyen en una proporción menor a la de sus maridos, entre aquellas que trabajan 40 horas y más esta cifra se reduce a 59 por ciento.

La inserción laboral de las cónyuges aparece también fuertemente vinculada a las aportaciones económicas de las cónyuges. ${ }^{11} \mathrm{El}$ trabajo no asalariado de las mujeres, y el asalariado pero sin recibir beneficios laborales, están vinculados con una mayor distancia entre los ingresos de éstas y de sus parejas. ¿Qué argumentos podrían esgrimirse para explicar este resultado? Uno de ellos es nuevamente la estrecha relación entre el trabajo no asalariado y el trabajo parcial. Como se ha mostrado en numerosas investigaciones, las cónyuges tienden a trabajan en actividades económicas no asalariadas, porque en la mayoría de los casos este tipo de empleo no requiere una jornada laboral de tiempo completo, lo que les permite continuar atendiendo los quehaceres domésticos. Un segundo argumento tiene que ver con el hecho de que las actividades no asalariadas o informales no favorecen la acumulación de experiencia laboral y de antigüedad que tenga como consecuencia una movilidad ascendente de los ingresos. Finalmente, entre las trabajadoras del sector informal se encuentran sobrerrepresentadas mujeres con trayectorias laborales intermitentes, es decir, mujeres que recurrentemente entran y salen de la actividad

${ }^{11}$ Como lo sugerimos antes, existe una conexión directa entre la inserción laboral del cónyuge y del jefe. Cónyuges y jefes que trabajan en su mayoría lo hacen en similares situaciones laborales. En alrededor de $60 \%$ de las parejas en las que la cónyuge trabaja como asalariada y recibe beneficios laborales, el jefe también trabaja en la misma condición. En el caso de cónyuges que trabajan como no asalariadas, ocurre exactamente lo mismo. 
económica (Cerrutti, en prensa). La intermitencia laboral de la mujer impacta directamente los ingresos percibidos al no permitir la acumulación de antigüedad y experiencia. ${ }^{12}$ Los hombres, en particular los jefes, tienen trayectorias laborales más estables, por lo que diferencias por género en la estabilidad laboral explicarían una parte significativa de los diferenciales salariales entre ambos miembros de la pareja.

Por último, las horas trabajadas por el jefe también tienen un efecto sobre los ingresos aportados por las cónyuges. Si el jefe trabaja de 20 a 39 horas por semana, es más probable que su cónyuge contribuya igual o más que él, mientras que si trabaja 40 o más esta relación se invierte. ${ }^{13}$

Las relaciones señaladas anteriormente podrían ser espurias, al estar más bien expresando el efecto de otros rasgos (por ejemplo, la fuerte asociación entre empleo no asalariado y trabajo de tiempo parcial). Para determinar los efectos netos de las características recién presentadas, se estimó un modelo de regresión lineal de mínimos cuadrados teniendo como variable dependiente la proporción de ingresos de la mujer en relación con el total de la pareja.

El cuadro 8 presenta los coeficientes del análisis multivariado. Un primer resultado de interés es que no es tanto el nivel educativo absoluto de la mujer el que influye en la proporción de ingresos generados por las cónyuges, como la relación entre el nivel educativo de ella y su pareja. Sólo la educación primaria completa de la cónyuge fue estadísticamente significativa. Dicho coeficiente señala una penalización en la proporción de ingresos de cónyuges con baja educación respecto de aquéllas con educación universitaria. Sin embargo, los coeficientes referidos a los niveles relativos de educación señalan más claramente el premio y la pérdida si ellas tienen, respectivamente, mayores o menores niveles educativos que sus esposos.

Debemos resaltar también que tanto la edad de las mujeres, como indicador del momento en el ciclo de vida, como el número de hijos y la presencia de hijos pequeños en el hogar son características

${ }^{12}$ Estudios empíricos recientes en Estados Unidos basados en información anual sobre participación laboral, muestran que la contribución económica de las mujeres en sus hogares depende en gran medida del número de semanas trabajadas a lo largo del año (Hayghe, 1993).

${ }^{13}$ Sólo $6 \%$ de los jefes con cónyuges que generan ingresos se encuentran trabajando por menos de 20 horas semanales, por lo tanto, es muy posible que la reversión en la relación que se observa para dicho grupo se deba al reducido número de casos. 


\section{CUADRO 8}

Resultados de regresión múltiple lineal de los determinantes individuales y del hogar en la contribución relativa de las cónyuges al total de ingresos de la pareja. Áreas urbanas de México, 1997

Variables independientes

Constante

Educación cónyuge

Menos de primaria completa

Primaria completa

Algún año de secundaria o preparatoria

Algún año de universidad

Edad cónyuge

Menos de 31 años

31 a 50 años

Más de 50 años

Horas trabajadas por la cónyuge

Menos de 20 horas

De 20 a 39 horas

40 o más horas

Inserción laboral de la cónyuge

Asalariada con beneficios

Asalariada sin beneficios

No asalariada

Hijos menores de 6 años

Número de hijos $(3 \mathrm{y}+)$

Relación de educación cónyuge/jefe

Cónyuge menor educación

Ambos la misma educación

Jefe menor educación

Horas trabajadas por el jefe

Menos de 20 horas

De 20 a 39 horas

40 y más horas

Inserción laboral del jefe

Asalariado con beneficios

Asalariado sin beneficios

No asalariado
Coeficientes $\beta$

$47.594 * * *$

0.247

$-1.596 * *$

$-0.891$

$-0.876^{*}$

$2.449 * * *$

$-8.461 * * *$

$4.223 * * *$

$-7.784 * * *$

$-9.578 * * *$

$0.914 * *$

$-1.174 * * *$

$-2.115^{* * * *}$

$3.431 * * *$

0.963

$-4.848 * * *$

0.596

$3.997 * * *$

Número de casos: 5829

$\mathrm{R}$ cuadrada $=0.23$

Notas: *** p.<.001, ** p.<.01, * p.<.05.

Fuente: Encuesta Nacional de Empleo Urbano, 1987 y 1997 (segundo trimestre). Datos procesados por los autores. 
que repercuten en la proporción de ingresos aportados por las cónyuges. Es relativamente inesperado el resultado sobre el efecto de la presencia de niños pequeños en el hogar, ya que pareciera tener un efecto bajo, pero positivo en la proporción de ingresos generados por la cónyuge. Una posible explicación a este resultado es que las cónyuges con hijos pequeños que trabajan y reciben ingresos estén representando un grupo muy selecto de mujeres, para las cuales el costo de oportunidad de salir al mercado de trabajo es tan alto que sólo pueden hacerlo en situaciones de ingreso muy ventajosas.

En cuanto a características relativas al trabajo, las horas trabajadas y la inserción laboral de ambos miembros de la pareja aparecen asociadas a la proporción de ingresos aportados por la cónyuge en la dirección esperada. Así, por ejemplo, la contribución de la cónyuge decrece en promedio ocho puntos porcentuales si ella trabaja menos de 20 horas semanales en relación con las que trabajan entre 20 y 39 horas, y cuatro puntos porcentuales si el jefe trabaja 40 o más horas.

Finalmente, son las mujeres asalariadas con beneficios (aquellas que trabajan en los sectores modernos de la economía) quienes generan los ingresos relativos mas elevados. Su porcentaje de ingresos relativos a los de sus maridos son superiores en casi diez y ocho puntos a los generados por las no asalariadas y las asalariadas sin beneficios, respectivamente. Asimismo, si los maridos trabajan como no asalariados los ingresos relativos de las mujeres son más elevados que si los maridos trabajan en relación de dependencia como asalariados.

\section{Consideraciones finales}

El aumento en el empleo de las mujeres durante las últimas dos décadas, en particular de las cónyuges, constituye una de las transformaciones más importantes de los mercados de trabajo de México. La relevancia de este fenómeno, sin embargo, excede el ámbito laboral. Por un lado, una parte significativa de este incremento ha estado asociado a procesos de crisis económica y reducción de los ingresos familiares y, por el otro, porque este proceso social y económico ha sido producto y motor de cambios significativos en las relaciones de género. En este trabajo se mostró que, entre 1987 y 1997, tuvo lugar un incremento en la proporción de parejas con ambos miembros 
participando en la actividad económica extradoméstica. Fue a partir de la creciente importancia de las mujeres (casadas o unidas) como trabajadoras que nos propusimos dar respuesta a dos interrogantes centrales para el estudio de las relaciones entre géneros: ¿En qué medida la creciente participación de las mujeres mexicanas en el mercado laboral ha modificado sustancialmente su nivel de dependencia económica?, y ¿cuáles son las condiciones que facilitan tanto como obstaculizan la participación de las mujeres en actividades económicas?

Un hallazgo significativo para las relaciones entre géneros fue que en las principales zonas urbanas de México, entre 1987 y 1997, la proporción de parejas con doble proveedor se incrementó significativamente. A partir de este resultado argumentamos la existencia de una concreta erosión del modelo tradicional del "jefe del hogar" como el único proveedor económico. Sin embargo, cuando consideramos la evolución de la relación entre los ingresos generados por el jefe y por la cónyuge, o en otras palabras, la contribución proporcional efectuada por las mujeres al total de los ingresos de la pareja, el panorama no resultó tan alentador. El aumento en el número de cónyuges mujeres que participaron en la fuerza de trabajo durante la pasada década no tuvo como consecuencia un cambio significativo en las contribuciones relativas de éstas a los ingresos de la pareja. Cuatro de cada diez mujeres continúan percibiendo ingresos cuyo valor monetario equivale a menos de la mitad de los ingresos del marido, y sólo dos de cada diez continúan generando ingresos mayores.

Si bien parte de la brecha de ingresos entre miembros de la pareja se debe a diferencias en capital humano y a factores institucionales que operan en el mercado de trabajo (segmentación ocupacional y discriminación sexual), otra parte encuentra explicación en los arreglos laborales específicos que existen entre varones y mujeres. La división sexual del trabajo, de hecho ya modificada en estos hogares con doble proveedor, se establece ahora en relación con el tipo y condiciones de trabajo en que ambos laboran. Aun en un contexto social y económico más propicio para el trabajo femenino fuera del hogar, las mujeres continúan siendo las principales responsables del trabajo doméstico y del cuidado de los niños. La mayor responsabilidad de la mujer trabajadora en tareas de reproducción cotidiana y generacional de los hogares, conlleva un menor "compromiso" de éstas con la actividad económica extradoméstica, lo cual necesariamente restringe la regularidad de su incorporación al mercado de trabajo, y sus 
oportunidades en ocupaciones de tiempo completo y estable. De esta manera, no es difícil suponer que la incorporación de la mujer a la fuerza de trabajo tendrá un mayor significado económico, una vez que los papeles del hombre y la mujer sean redefinidos en función de una responsabilidad doméstica más equilibrada.

Por lo anterior es que consideramos necesario prestar mayor atención a los arreglos laborales entre miembros de la pareja, es decir a las particulares circunstancias (en términos de tipo de trabajo, condiciones laborales, horas trabajadas, etc.) que facilitan (o restringen) la participación de ambos miembros de la pareja en actividades económicas. A diferencia de los estudios tradicionales sobre los determinantes de la participación femenina en los mercados de trabajo, centrados fundamentalmente en la influencia de factores asociados con el capital humano, el ciclo de vida individual y los contextos familiares, nuestra investigación intentó adicionalmente indagar sobre las relaciones existentes entre la situación laboral de las cónyuges y las del jefe del hogar. Así, partimos de la hipótesis de que la propensión a trabajar, el tipo de trabajo que desempeña la mujer, y su nivel relativo de ingresos, no son independientes de la naturaleza y características del trabajo de su pareja. Los resultados empíricos validan positivamente nuestra argumentación en relación con los arreglos laborales de las parejas. Así, por ejemplo, es más probable que una cónyuge trabaje si el jefe del hogar se desempeña como trabajador independiente o trabaja menos de 40 horas a la semana. Adicionalmente se encontró que los arreglos laborales entre parejas económicamente activas varían según el ciclo de vida de las parejas, y que los arreglos más típicos fueron los de ambos miembros trabajando como asalariados con beneficios laborales y el de jefes independientes con cónyuges que se desempeñan como trabajadoras familiares no remuneradas. Finalmente, se mostró la existencia de un deterioro importante en las condiciones laborales de ambos miembros de la pareja entre 1987-1997, siendo dicho deterioro más pronunciado entre las parejas jóvenes.

Nuestros resultados apuntan la necesidad de profundizar en el conocimiento de los arreglos laborales de las parejas con el objeto de contribuir al mejor entendimiento, por un lado, de los efectos que tienen los cambios en las condiciones del mercado de trabajo en la dinámica de la oferta de trabajo (femenina y masculina), y por el otro, de la situación de desventaja económica, por parte de las mujeres trabajadoras. 


\section{Apéndice}

Modelos de regresión logística y lineal

a) Modelos de regresión logística dicotómicos para estimar las probabilidades de que ambos miembros de la pareja trabajen. El primer modelo incluye sólo variables referidas a la cónyuge y a la familia, mientras que el segundo incorpora variables referidas al trabajo del jefe.

\section{Modelo 1:}

$$
\log \frac{\dot{P}}{1-P}=\alpha+\beta_{i} E d a d_{i}+\delta_{j} E d u c_{j}+\chi_{k} H_{i j P e q}+\varpi_{l} N u m H i j_{l}
$$

Modelo 2:

$$
\begin{gathered}
\log \frac{P}{1-P}=\alpha+\beta_{i} \text { Edad }_{i}+\delta_{j} \text { Educ }_{j}+\chi_{k} \text { HijPeq }_{k}+\varpi_{l} \text { NumHij }_{l}+ \\
\gamma_{m} \text { InsJef }_{m}+\eta ._{n} \text { IngJef }_{n}+\iota_{. o} \text { HrsJef }_{o}
\end{gathered}
$$

donde:

$P=$ Probabilidad de que ambos miembros de la pareja trabajen;

$\alpha=$ constante;

$\beta, \delta, \chi, \Phi, \gamma, \eta, \mathrm{t}=$ coeficientes;

Edad (grupos de edad), Educ (nivel de educación de la cónyuge), Hij$P e q$ (presencia de hijo menor de seis años y de otrạ mujer adulta fuera de la fuerza de trabajo), NumHij (número de hijos) InsJef (inserción laboral del jefe), IngJef (cuartiles de ingresos del jefe), y HrsJef (horas trabajadas por el jefe), son las variables independientes;

$i, j, k, l, m, n$ y $o$ son el conjunto de variables dicotómicas que asumen valor 1 , denotando la presencia del atributo, o 0 , denotando su ausencia.

b) Modelo de regresión lineal cuya variable dependiente es la proporción de ingresos de la mujer en relación con el total de la pareja.

$$
\begin{gathered}
Y=\alpha+\beta_{i} \operatorname{Edad}_{i}+\delta_{j} E_{d u c_{j}}+\chi_{k} \text { Hijos }_{k}+\gamma_{l} \text { InsCony }_{l}+\eta_{m} \text { HrsCony }_{m} \\
+\iota_{n} \text { EduRel }_{n}+\kappa_{o} \text { HrsJef }_{o}
\end{gathered}
$$


donde:

$Y=$ es la proporción de los ingresos de la mujer en el total de ingresos de la pareja;

$\alpha=$ constante;

$\beta, \delta, \chi, \gamma, \eta, \mathrm{l}, \kappa=$ coeficientes;

Edad (grupos de edad), Educ (nivel de educación de la cónyuge), Hijos (presencia de hijos menores de seis años), InsCony (inserción laboral de la cónyuge), HrsCony (horas trabajadas por la cónyuge), EduRel (educación relativa cónyuge/jefe) y HrsJef (horas trabajadas por el je$\mathrm{fe}$, , son las variables independientes. Las variables independientes corresponden por lo tanto: a la cónyuge, al jefe, a la relación entre ambos, y al hogar.

$i, j, k, l, m, n, \mathrm{y} o$ son el conjunto de variables dicotómicas que asumen valor 1 , denotando la presencia del atributo, o 0 , denotando su ausencia.

\section{Bibliografía}

Barret, Michelle (1980),Women's Oppressions Today: Problems in Marxist Feminist Analysis, Londres, Verso Editions.

Benería, Lourdes y Martha Roldán (1987), The Crossroads of Class and Gender. Industrial Homework, Subcontracting and Household Dynamics in Mexico City, Chicago, University of Chicago Press.

Blumberg, Rae L. (1991), "Introduction", en Rae L. Blumberg (ed.) Gender, Family and the Economy, Newbury Park, Sage.

Cerrutti, Marcela (1997), "Coping with Opposing Pressures: A Comparative Analysis of Women's Intermittent Participation in the Labor Force in Buenos Aires and Mexico City", tesis de doctorado, The University of Texas at Austin.

_- (en prensa), "Intermittent Employment among Married Women: A Comparative Study of Buenos Aires and Mexico City", Journal of Comparative Family Studies.

Christenson, B., Brígida García, y Orlandina de Oliveira (1989), "Los múltiples condicionantes del trabajo femenino en México", Estudios Sociológicos, vol. 20, pp. 251-280.

England, Paula (1992), Comparable Worth. Theories and Evidence, Nueva York, Aldine de Gruyter.

Estrella, Gabriel y René Zenteno (1998), "Integración de la mujer a los mercados laborales urbanos en México: 1988-1994", Estudios Demográficos y Urbanos, vol. 14, núm. 3 (42), pp. 675-740.

Fussell, Elizabeth y René Zenteno (1998), " Spatial Differences in Wage and Non-Wage Female Labor Force Participation in Mexico", Madison, Cen- 
ter for Demography and Ecology, University of Wisconsin-Madison (Working Paper Series, 97-11).

García, Brígida y Orlandina de Oliveira (1994), Trabajo femenino y vida familiar en Mexico, México, El Colegio de Mexico.

González de la Rocha, Mercedes, Agustin Escobar, y María Martínez Castellanos (1990), "Estrategias vs. conflicto: reflexiones para el estudio del grupo doméstico en época de crisis", en Guillermo de la Peña $e t$ al. (eds.) Crisis, conflicto y sobrevivencia. Estudios sobre la sociedad urbana en México, Guadalajara, Universidad de Guadalajara/CIESAS.

Hardill, Irene et al. (1997), "Who Decides What? Decision Making in Dual-Ca'reer Households", Work, Employment and Society, vol. 11, núm. 2, pp. 313326.

Hartman, Heidi (1976), "Capitalism, Patriarchy and Job Segregation by Sex", Signs, núm. 1, pp. 137-168.

Hayghe, Howard V. (1993), "Working Wives's Contributions to Family Incomes”, Monthly Labor Review, vol. 116, núm. 8, pp. 39-45.

Hood, Jane (1983), Becoming a Two-Job Family, Nueva York, Preaeger.

Huber, Joan y Glenna Spitze (1983), Sex Stratification. Children, Household, and Jobs, Nueva York, Academic Press.

Kincade Oppenheimer, Valerie (1982), Work and the Family. A Study in Social Demography, Nueva York, Academic Press.

Mason, Karen Oppenheim (1996), "Wives' Economic Decision-Making Power in the Family in Five Asian Countries", documento de trabajo núm. 86, Honolulu, East-West Center.

Oppenheim Masson, Karen (1996), "Wife's Economic Decision-Making Power in the Family in Five Asian Countries", East-West Center Working Paper, núm. 86.

Roldán, Martha (1988), "Renegotiating the Marital Contract. Intrahousehold Patterns of Money Allocation and Women's Subordination among Domestic Outworkers in Mexico City", en Daisy Dwyer y Judith Bruce (eds.) A Home Divided. Women and Income in the Third World, Stanford, Stanford University Press.

Safa, Helen (1995), The Myth of the Male Breadwinner. Women and Industrialization in the Caribbean, Boulder, Westview Press.

Selby, Henry et al. (1996), "The Women in Mexico and the Neoliberal Revolution", Anuario de Estudios Urbanos, núm. 3, pp. 75-92.

Sorensen, Annemette y Sara McLanahan (1987), "Married Women's Economic Dependency, 1940-1980", American Journal of Sociology, vol. 93, núm. 3 , pp. 659-687.

Tiano, Susan (1994), Patriarchy on the Line. Labor, Gender and Ideology in the Mexican Maquila Industry, Filadelfia, Temple University Press.

Zenteno, René (1998), "Crisis económica y determinantes de la oferta de trabajo femenino en México: 1994-1995", Estudios Demográficos y Urbanos, vol. 14, núm. 2 (41), pp. 353-381. 